\title{
Food store access and household fruit and vegetable use among participants in the US Food Stamp Program
}

\author{
Donald Rose* and Rickelle Richards \\ Department of Community Health Sciences, School of Public Health and Tropical Medicine, Tulane University, \\ 1440 Canal Street, Suite \#2301, New Orleans, LA 701 12, USA
}

Submitted 11 March 2004: Accepted 8 June 2004

\begin{abstract}
Objective: Recent research on access to food among low-income populations in industrialised countries has begun to focus on neighbourhood food availability as a key determinant of dietary behaviour. This study examined the relationship between various measures of food store access and household fruit and vegetable use among participants in the Food Stamp Program, America's largest domestic food assistance programme.

Design: A secondary data analysis was conducted using the 1996-97 National Food Stamp Program Survey. The survey employed a 1-week food inventory method, including two at-home interviews, to determine household food use. Separate linear regression models were developed to analyse fruit and vegetable use. Independent variables included distance to store, travel time to store, ownership of a car and difficulty of supermarket access. All models controlled for a full set of socioeconomic variables.

Subjects: A nationally representative sample of participants $(n=963)$ in the Food Stamp Program.

Results: After controlling for confounding variables, easy access to supermarket shopping was associated with increased household use of fruits (84 grams per adult equivalent per day; $95 \%$ confidence interval 5,162 ). Distance from home to food store was inversely associated with fruit use by households. Similar patterns were seen with vegetable use, though associations were not significant.

Conclusions: Environmental factors are importantly related to dietary choice in a nationally representative sample of low-income households, reinforcing the importance of including such factors in interventions that seek to effect dietary improvements.
\end{abstract}

Keywords

Fruit and vegetable consumption Food environment Supermarket access Household survey Low-income population Food Stamp Program
Substantial evidence has accumulated on the health benefits of fruit and vegetable consumption ${ }^{1-3}$. The beneficial role of fruits and vegetables is so well accepted in the scientific community that recommendations for their consumption form an integral part of government health advice. Since 1980 in the USA, the Dietary Guidelines for Americans has highlighted the importance of fruits and vegetables as separate food groups ${ }^{4}$. The latest health goals for the nation, encapsulated in Healthy People 2010, also outline specific targets for increasing the consumption of these foods 5 .

Despite the clear advice from the scientific community, intakes of fruits and vegetables among Americans fall significantly below recommendations. Only $28 \%$ of Americans meet the recommendation for fruit consumption ( $\geq 2$ servings per day) and only 49\% meet the recommendation for vegetable consumption $(\geq 3$ servings per day $)^{6}$. The statistics are even worse for the low-income population, in which only $23 \%$ and $42 \%$ meet the recommendations for fruits and vegetables, respectively 5 .

Nutritionists, social scientists and policy-makers have long realised the importance of economic factors in determining nutrient intakes, household income being one of the key ones. Early studies showed that individuals from households in poverty were more likely to exhibit nutritional deficiencies or have diets low in various nutrients 7,8 . The Food Stamp Program expanded tremendously in the 1970 s, as a response to these studies and other more visible press accounts of hunger in America9 . Historically, it was by increasing the purchasing power of the poor that the Program sought to improve nutritional outcomes.

The issue of access to food has taken on a more nuanced meaning as researchers consider not just the resources of individual households, but also the neighbourhoods in which they reside. Despite the existence of a highly industrialised food distribution 
system, there is a considerable degree of unevenness in the USA. For example, Kaufman et al. have shown that supermarkets located in urban and rural areas charge higher prices for foods, compared with those in suburban neighbourhoods, in part because their operating costs are higher ${ }^{10}$. Unfortunately, it is in urban and rural areas where the concentration of poor households is highest.

Recently, public health and nutrition researchers have documented the influence of neighbourhood environmental factors on food choices. Morland et al. found that African Americans residing in census tracts with one or more supermarkets were more likely to meet their fruit and vegetable recommendations than those who did not $^{11}$. Edmonds et al. found a correlation between restaurant availability of juices or vegetables and the consumption of these foods by African American Boy Scouts residing in Houston, Texas ${ }^{12}$. In the UK, neighbourhoods lacking retail food stores have been termed 'food deserts' 13 . Recent evidence indicates that introduction of a new supermarket in a previous food desert is associated with a significant increase in fruit and vegetable consumption ${ }^{14}$.

These studies on food environments have added greatly to the literature; however, they provide only partial answers to a complex puzzle. The issue of access to food involves not only the food environment, but also how people interact with that environment. For example, if neighbourhoods are unsafe for walking, household characteristics, such as ownership of a car, might have much greater weight in determining access to food shopping opportunities than distance to the store. On the other hand, a household without a car but on a public transportation route may have better access, if getting in the car involves a time-consuming trip through city traffic. The time issue is important and brings in an entirely new dimension to the access equation. All else equal, a person with less time available to prepare household meals - for example, because of being a single parent or having to work to raise a comparable income - will have more difficulty in accessing food stores.

This paper explores how a number of these factors influence fruit and vegetable consumption among lowincome US households. We utilise the National Food Stamp Program Survey (NFSPS), which provides information on many of the key access issues that are determined at the intersection between household behaviour and environment. Unlike many neighbourhood environmental studies, we are also able to control for diet attitudes and awareness about dietary recommendations in our multivariate models.

\section{Methods}

\section{Data source}

The survey at the core of our secondary data analysis, the NFSPS, was conducted by Mathematica Policy Research,
Incorporated under contract to the Food and Nutrition Service of the US Department of Agriculture (USDA). The survey collected data on participant demographics, shopping behaviours, food use and dietary knowledge and attitudes from June 1996 to January 1997.

The NFSPS used a two-stage sample design. In the first stage, 43 primary sampling units were chosen. Usually these were entire counties randomly selected with probability proportional to size. In the second stage, households participating in the Food Stamp Program were randomly selected from local and/or state programme participant lists. The response rate for the household interview alone was 69\%; it was 67\% when both the household interview and the food use component were considered. Our analytical sample $(n=963)$ contains all of these households with complete information on the variables described below. This amounted to $90 \%$ of those who completed the food use component, or 60\% 0.67 times 0.90 ) of the total eligible respondent households. Additional details concerning the sample design have been given previously ${ }^{15}$.

\section{Outcome variables}

Weekly bousehold food use consists of all foods used from the home food supply, including foods used within the home and foods prepared at home but taken elsewhere to eat (for example, lunch made at home but eaten at work), as well as purchased and home-grown foods. It differs from the food eaten by individuals in that it does not include foods bought and eaten outside the home. It also differs from individual food intake in that plate waste is included. In economic terms, food is considered 'consumed' (i.e. acquired and used) by the household even if, for example, some of it ends up as refuse. Accordingly, we use 'consumption' and 'use' interchangeably throughout this paper.

We developed two outcome variables, household fruit use and household vegetable use, expressed in grams per adult male equivalent per day $\left(\mathrm{g} \mathrm{ae}^{-1} \mathrm{day}^{-1}\right)$. Variables available on the NFSPS database categorised individual food items into six broad food groups that we then aggregated into either fruits or vegetables. The six groups were: fruits high in vitamin $\mathrm{C}$; other fruits; vegetables high in vitamin $\mathrm{A}$ or $\mathrm{C}$; other vegetables; potatoes; and mixed dishes in which the primary ingredient was a vegetable. We divided the weekly amounts on the database by seven to scale the variables to daily usage.

Since households vary in size, we also wanted these consumption variables to be expressed in per person amounts. Rather than divide by the number of persons, we divided the consumption variables by the number of adult male equivalents in each household. This is a common technique in consumption analysis for normalising intakes to relative nutritional needs, and avoids the problem of a simple 'per capita' normalisation in which an infant could get counted the same as an adult. Each member's food 
energy needs were scaled to the needs of an adult male (19-50 years of age), using the 1989 recommended energy intakes (REIs) ${ }^{16}$ which were in effect at the time of this survey. For example, a 30-year-old adult male had an REI of $2900 \mathrm{kcal} \mathrm{day}^{-1}$, while a 30-year-old woman had an REI of $2200 \mathrm{kcalday}^{-1}$. Therefore, in terms of approximate energy needs, a two-person household consisting of a man and a woman in their thirties would be equivalent to 1.76 adult males; the man would count as 1 and the woman would count as $0.76(2200 \div 2900)$.

\section{Explanatory variables}

Self-reported store access variables included an indicator of whether the household owned a car as well as information on the store in which it purchased most of its food, including whether or not this store was a supermarket, and the distance and round-trip travel time to it.

To explore gradations of store access, we created a trichotomous supermarket access variable that combined the supermarket shopping, travel time and car ownership variables. One group of households, with little access to supermarkets, reported buying most of their food from other types of store. A second group, labelled 'moderate supermarket access', reported buying most of their food from supermarkets, but did not own a car and spent $30 \mathrm{~min}$ or longer in round-trip travel to their store. A third group had easy access to supermarkets: they bought most of their food there, and either owned a car or had a roundtrip travel time of less than 30 min to their supermarket. We experimented with various versions of this composite variable, all of which included information on shopping at a supermarket as well as different combinations of the urbanisation, car ownership, access to a car, travel time to store or distance to store variables. We wanted a variable that could capture the notion that urban residents who do not own a car might still be able to get to a store relatively quickly (if residing on a public transportation route), whereas for many rural residents, a car might be more important than travel time (since getting anywhere takes time). We chose the version described above, because it captured key dimensions of the access issue, was simple to communicate, and yielded similar results to our other versions of this variable in the multivariate models.

The NFSPS instrument has various questions addressing the diet knowledge and attitudes of household respondents. Analogous to work done by Gleason et al. ${ }^{17}$ and Haines et $a .^{18}$, we developed an attitudinal factor describing the importance of dietary choices to the respondent based on an average of 10 specific questions. All of these questions started the same - 'Is it very important, somewhat important, not too important or not important at all to...' - and ended with 10 different nutrition-related behaviours based on standard government dietary advice, such as: choose foods low in saturated fat; choose a daily diet with 5 or more servings of fruits and vegetables; choose foods with adequate fibre; etc. Attitudes ranged from 1 (very important) to 4 (not important at all). A dichotomous variable was then created indicating an attitude that dietary choices were somewhat to very important (average score $\leq 2.0$ ) or not important (average score $>2.0$ ). Respondents were asked if they were familiar with the USDA Food Guide Pyramid ${ }^{19}$ and if so, were then asked to list types of food included in the pyramid. Those indicating they were familiar with the pyramid and able to list one or more foods or food groups in it were classified as having some awareness of the food guide recommendations.

Other independent variables likely to exert important influences on food consumption were also included in our analyses, such as urbanisation (urban, mixed, rural); household income per adult male equivalent; household size in adult male equivalents; single parent status; schooling (less than high school, high school graduate or equivalent, or some college), employment status (20 h or more per week); and race/ethnicity (white, African American, Hispanic, other) of the household respondent.

\section{Statistical analysis}

Basic file management, including creation of our analytical files from the original NFSPS archive, was conducted using SPSS, version 11.0 (SPSS, Inc., Chicago, IL, USA, 2001). Our descriptive statistics as well as multivariate analyses made use of statistical weights provided with the NFSPS. These weights were developed to compensate for differential probabilities of selection and to adjust for the effects of non-response ${ }^{15}$. To account for the complex sample design, we used the jackknife method of WesVar version 4.2 (Westat, Inc., Rockville, MD, USA, 2000), which uses replicate techniques to estimate standard errors.

\section{Results}

The sociodemographic characteristics of the NFSPS sample are shown in Table 1. A majority of households lived in urban areas. Households headed by African Americans comprised 39\% of the sample, while those headed by Hispanics and whites accounted for 13\% and $44 \%$, respectively. A majority of household respondents were either high school graduates or equivalent or had more schooling beyond this. Sixty-three per cent of households had incomes below $75 \%$ of the poverty level, and about $14 \%$ were employed for 20 or more hours in the previous week.

Even in this low-income sample of Food Stamp Program participants, 93\% of households bought most of their food from supermarkets (Table 2). For 38\% of households, the store where they bought most of their food was within a mile of their house, while 27\% travelled over 5 miles. Round-trip travel time to the store and back was less than 30 min for over two-thirds of households, and a little under half of households owned a car. In our composite supermarket access variable, $76 \%$ had easy access. 
Table 1 Socio-economic characteristics of the analytical sample of Food Stamp Program participants $(n=963)$, National Food Stamp Program Survey, 1996-1997

\begin{tabular}{lc}
\hline Characteristic & Frequency (\%) \\
\hline Urbanisation & \\
Mixed & 30.9 \\
Urban & 54.4 \\
$\quad$ Rural & 14.7 \\
Race/ethnicity of household respondent & \\
$\quad$ White & 44.1 \\
African American & 39.4 \\
Hispanic & 13.3 \\
Other & 3.2 \\
Education of household respondent & \\
$\quad<12$ years & 47.5 \\
High school graduate & 37.4 \\
$>12$ years & 15.2 \\
Single parent & \\
$\quad$ No & 67.3 \\
Yes & 32.7 \\
Household size & \\
1 & 25.0 \\
2 & 17.9 \\
3 or 4 & 38.7 \\
$5+$ & 18.4 \\
Household income & \\
$\quad<75 \%$ poverty level & 62.9 \\
$\geq 75 \%$ poverty level & 37.1 \\
Hours worked by household respondent last week & \\
$<20$ & 85.9 \\
$\geq 20$ & 14.1 \\
\hline
\end{tabular}

Most of the access variables were related to household fruit usage in the expected direction, although differences were not always statistically significant (Table 2). Those living within a mile of their principal food store consumed
$285 \mathrm{gae}^{-1}$ day $^{-1}$ of fruit, while those living greater than 5 miles consumed $220 \mathrm{~g} \mathrm{ae}^{-1}$ day $^{-1}$, a difference of about $65 \mathrm{~g} \mathrm{ae}^{-1}$ day $^{-1}(P<0.023)$. Those with shorter round-trip travel times to their principal food store consumed more, 269 versus $244 \mathrm{~g} \mathrm{ae}^{-1}$ day $^{-1}$, although this difference was not statistically significant. Our combined supermarket access variable showed that fruit consumption increased as access became easier. One unexpected result was that those who owned a car consumed lower amounts of fruits and vegetables. Elderly and single-person households consumed proportionately greater amounts of these foods (data not shown). This may have confounded the 'consumption-car ownership' relation, since these households had lower rates of car ownership. Table 2 presents further results of the bivariate analysis.

The results from our multivariate models show the mean differences in household fruit and vegetable use by access, attitude and awareness variables, each being adjusted for the full set of socio-economic variables (Table 3, top section). Households that purchased most of their food from supermarkets consumed $82 \mathrm{gae}^{-1}$ day $^{-1}$ (95\% confidence interval (CI) 7,157$)$ more fruit than the reference group of households that shopped from other stores. Households living further than 5 miles from their principal store consumed significantly less fruit than the reference group of those living within a mile. Our supermarket access variable that combined store, travel time and car ownership revealed that those with easy supermarket access consumed greater amounts than did those with no access. Those with

Table 2 Mean household fruit and vegetable use of Food Stamp Program participants, by store access, diet attitude and awareness, National Food Stamp Program Survey, 1996-1997

\begin{tabular}{|c|c|c|c|c|c|}
\hline & \multirow[b]{2}{*}{ Frequency (\%) } & \multicolumn{2}{|c|}{ Fruits $\left(\mathrm{g} \mathrm{ae}^{-1} \text { day }^{-1}\right)^{\star}$} & \multicolumn{2}{|c|}{ Vegetables $\left(\mathrm{gae}^{-1} \text { day }^{-1}\right)^{*}$} \\
\hline & & Mean (SEM) & $P$-value $†$ & Mean (SEM) & $P$-value $\dagger$ \\
\hline \multicolumn{6}{|c|}{ Supermarket shopper } \\
\hline No & 7.4 & $196(36)$ & & $287(50)$ & \\
\hline Yes & 92.6 & 266 (17) & 0.067 & $322(27)$ & 0.526 \\
\hline \multicolumn{6}{|l|}{ Distance to store } \\
\hline$\leq 1$ mile & 38.1 & $285(21)$ & & $323(37)$ & \\
\hline $1-5$ miles & 34.7 & $263(25)$ & 0.426 & $313(32)$ & 0.799 \\
\hline$>5$ miles & 27.2 & $220(25)$ & 0.023 & $315(31)$ & 0.829 \\
\hline \multicolumn{6}{|c|}{ Travel time $<30 \mathrm{~min}$} \\
\hline No & 30.7 & $244(25)$ & & $306(31)$ & \\
\hline Yes & 69.3 & 269 (19) & 0.422 & $325(27)$ & 0.46 \\
\hline \multicolumn{6}{|l|}{ Owns a car } \\
\hline No & 52.4 & $281(21)$ & & $348(30)$ & \\
\hline Yes & 47.6 & $240(18)$ & 0.069 & 287 (29) & 0.039 \\
\hline \multicolumn{6}{|c|}{ Supermarket access } \\
\hline None & 7.4 & $196(36)$ & & $287(50)$ & \\
\hline Moderate & 16.1 & $258(40)$ & 0.255 & $292(32)$ & 0.927 \\
\hline Easy & 76.5 & 268 (18) & 0.061 & $328(29)$ & 0.462 \\
\hline \multicolumn{6}{|c|}{ Attitude towards diet } \\
\hline Not important & 23.6 & $216(20)$ & & $273(26)$ & \\
\hline Important & 76.4 & $275(18)$ & 0.007 & $334(30)$ & 0.059 \\
\hline \multicolumn{6}{|c|}{ Awareness of diet guidelines } \\
\hline Not aware & 51.9 & $247(20)$ & & $294(23)$ & \\
\hline Aware & 48.1 & 276 (19) & 0.177 & 347 (35) & 0.079 \\
\hline
\end{tabular}

SEM - standard error of the mean.

${ }^{*}$ Grams of foods used by the household from home supplies per adult equivalent per day.

$\dagger P$-value for a difference between indicated group and the reference (the first group for each variable). 
Table 3 Adjusted mean differences in household fruit and vegetable usage*, by store access, diet attitude and awareness, National Food Stamp Program Survey, 1996-1997

\begin{tabular}{|c|c|c|c|c|c|c|}
\hline & & Fruits & & & getables & \\
\hline & $\begin{array}{c}\text { Mean } \\
\text { difference }\end{array}$ & $\begin{array}{l}\text { Lower } \\
\text { bound }\end{array}$ & $\begin{array}{l}\text { Upper } \\
\text { bound }\end{array}$ & $\begin{array}{c}\text { Mean } \\
\text { difference }\end{array}$ & $\begin{array}{l}\text { Lower } \\
\text { bound } \dagger\end{array}$ & $\begin{array}{l}\text { Upper } \\
\text { bound } †\end{array}$ \\
\hline Individual modelsł & & & & & & \\
\hline Supermarket shopper & 82 & 7 & 157 & 40 & -61 & 141 \\
\hline $\begin{array}{l}\text { Distance to store: } 1-5 \text { miles } \\
\text { Distance to store: }>5 \text { miles }\end{array}$ & $\begin{array}{l}-15 \\
-62\end{array}$ & $\begin{array}{r}-64 \\
-117\end{array}$ & $\begin{array}{r}34 \\
-7\end{array}$ & $\begin{array}{l}-20 \\
-36\end{array}$ & $\begin{array}{l}-101 \\
-108\end{array}$ & $\begin{array}{l}61 \\
35\end{array}$ \\
\hline Travel time $<30 \mathrm{~min}$ & 23 & -41 & 88 & 30 & -22 & 81 \\
\hline Owns a car & -13 & -63 & 38 & -30 & -78 & 19 \\
\hline $\begin{array}{l}\text { Supermarket access: moderate } \\
\text { Supermarket access: easy }\end{array}$ & $\begin{array}{l}64 \\
86\end{array}$ & $\begin{array}{r}-39 \\
7\end{array}$ & $\begin{array}{l}166 \\
164\end{array}$ & $\begin{array}{r}-7 \\
51\end{array}$ & $\begin{array}{r}-106 \\
-55\end{array}$ & $\begin{array}{r}92 \\
156\end{array}$ \\
\hline Diet attitude: important & 63 & 16 & 111 & 75 & 12 & 139 \\
\hline Aware of Food Guide Pyramid guidelines & 46 & -3 & 94 & 80 & 16 & 145 \\
\hline Joint model| & & & & & & \\
\hline Supermarket access: moderate & 66 & -36 & 169 & -2 & -102 & 98 \\
\hline Supermarket access: easy & 84 & 5 & 162 & 48 & -57 & 153 \\
\hline Diet attitude: important & 56 & 9 & 102 & 61 & 4 & 119 \\
\hline Aware of Food Guide Pyramid guidelines & 36 & -11 & 82 & 67 & 8 & 126 \\
\hline
\end{tabular}

${ }^{*}$ All differences are with respect to the reference group for each variable (e.g. owns a car vs. does not own a car) and are adjusted for urbanisation, household income and size, and race/ethnicity, schooling, single parent status and employment status of the household respondent. Differences are in grams of food used by the household from home supplies per adult equivalent per day.

† Lower and upper bounds of the $95 \%$ confidence interval.

\# 'Individual model' results are based on five separate models, one for each variable in this column (and control for variables listed in the first footnote), while the 'joint model' considers supermarket access, diet attitude and awareness simultaneously.

moderate access to supermarkets had a level of consumption that was in between the two groups. Those for whom dietary choices were important as well as those who had some awareness of the Food Guide Pyramid recommendations also consumed greater quantities of fruits, though the latter relationship was not statistically significant.

The results on vegetable consumption generally followed the same pattern as for fruit consumption, although few of the differences were statistically significant. The diet attitude and awareness variables were exceptions to this, accounting for differences on the order of $75-80 \mathrm{~g} \mathrm{ae}^{-1} \mathrm{day}^{-1}$, for those who felt that diet choices were important or who were aware of pyramid guidelines, versus those who were not.

In the bottom of Table 3, we present results from our joint model, which included the combined supermarket access variable, the diet attitude and awareness variables and all of the covariates used to adjust mean differences in the top section of Table 3. Easy supermarket access was associated with a significantly greater fruit consumption, but not vegetable consumption. The opposite was true for the diet awareness variable, whereas attitude was significantly related to both fruit and vegetable consumption.

\section{Discussion}

Our investigation of a nationally representative sample of households participating in the US Food Stamp Program indicates that access to supermarket shopping did not appear to be a major problem for this group as a whole. Over $90 \%$ of households in this sample bought most of their food from supermarkets and close to three-quarters of households were within 5 miles of their principal store. Despite the fact that a majority of households did not own a car, the combination of short distances and other forms of transportation accounted for approximately two-thirds of households making a round-trip to their supermarket in less than $30 \mathrm{~min}$. When supermarket shopping, car ownership and travel time to store were combined into one variable, we found that $76 \%$ of Food Stamp households had relatively 'easy' access to a supermarket. Of course, this also indicates a quarter of households had only moderate or virtually no access to a supermarket.

Our results clearly show that access variables do matter, especially for household fruit consumption. Our multivariate results show that those living greater than 5 miles away from their principal food store consumed $62 \mathrm{~g} \mathrm{ae}^{-1}$ day $^{-1}$ fruit less than those living within a mile. For vegetables, the difference between the two groups was $36 \mathrm{~g} \mathrm{ae}^{-1}$ day $^{-1}$, although not statistically significant. In our joint multivariate model, those with easy access to a supermarket consumed $84 \mathrm{gae}^{-1}$ day $^{-1}$ fruit more than those with no access. For vegetables, the difference between these two groups was $48 \mathrm{~g} \mathrm{ae}^{-1} \mathrm{day}^{-1}$, although not statistically significant.

Unfortunately, translation programs do not exist to convert the amounts in the food database from NFSPS into common serving sizes, such as those used in the USDA Food Guide Pyramid. Fruit and vegetable servings vary 
tremendously in size; weights for Pyramid servings of raisins ( $1 / 4$ cup), lettuce ( 1 cup), apples ( $1 / 2$ cup chopped) and orange juice (3/4 cup) are 36, 55, 63 and $186 \mathrm{~g}$, respectively $^{19,20}$. Typically, $80 \mathrm{~g}$ is considered an average weight for a serving of fruits and vegetables ${ }^{3}$. Thus, those with easy supermarket access consumed about 1 serving $\mathrm{ae}^{-1}$ day $^{-1}$ more fruits than those with no access.

These results are certainly plausible, since, in general, supermarkets have a better selection of fruits and vegetables than small food stores ${ }^{21}$ and their prices are lower ${ }^{10}$. However, due to methodological differences, it is difficult to compare our specific results with other studies that have investigated the relationship between neighbourhood access and fruit and vegetable intakes. Although Edmonds et al. found a correlation between restaurant availability of juices or vegetables and the consumption of these foods by young boys, they did not find a significant association with their grocery store measure ${ }^{12}$. However, store availability was based on shelf space devoted to particular food products, rather than distance to the store or whether one was present in the census tract. Morland et al. did find a positive relationship between supermarket existence in census tracts and fruit and vegetable consumption ${ }^{11}$. Their results are presented in terms of likelihood of meeting recommendations for fruits and vegetables, rather than in mean amounts consumed; again making direct comparisons to our work difficult. However, a commonality among these early studies and ours is that neighbourhood access is an important correlate of consumption.

While the relationship between consumption and easy supermarket access is positive for both fruits and vegetables, the magnitude is higher for fruits than for vegetables ( 84 vs. $48 \mathrm{gae}^{-1} \mathrm{day}^{-1}$ ) and is statistically significant only for fruits. One hypothesis that could explain this difference is related to shelf-life. If, on average, the vegetables consumed by these households had a longer shelf-life than the fruits they consumed, then purchases could have been made less frequently, diminishing the importance of easy access. A second hypothesis is that we have underestimated total vegetable consumption, because (owing to the NFSPS food file grouping system) we were not able to include the vegetable portion of mixed dishes that were primarily composed of grains or meats. If grain- or meat-based mixed dishes are more available at supermarkets than neighbourhood groceries, then exclusion of the vegetables from these dishes could have diminished the association of easy supermarket access with vegetable consumption. However, for each of these two hypotheses, one could make reasonable arguments to the contrary (e.g. some fruits have a longer shelf-life than some vegetables). Further research is needed to determine which, if either, is correct.

A distinguishing feature of our research is that we were able to control for a full set of socio-economic factors that affect consumption. In addition to the usual demographics, we also controlled for current employment and single parent status. We hypothesised that households in which the person responsible for food preparation worked would have less time available for food shopping and preparation. Our combined multivariate model supports this, indicating that less fruits $\left(-65 \mathrm{~g} \mathrm{ae}^{-1} \mathrm{day}^{-1}\right.$, $P=0.017)$ and vegetables $\left(-50 \mathrm{~g} \mathrm{ae}^{-1} \mathrm{day}^{-1}, P=0.075\right)$ were consumed when the household respondent worked 20 or more hours per week (data not shown). Single parenthood is also likely to reduce the time available for food shopping and preparation, and our multivariate results for vegetable use $\left(-45 \mathrm{~g} \mathrm{ae}^{-1} \mathrm{day}^{-1}, P=0.067\right)$ support this. We cannot distinguish whether the potential time constraint on consumption represented by these variables was related to shopping (and thus perhaps linked to access) or food preparation. However, our control for these time-dependent variables in our multivariate model ensures that they did not confound our access measure, an approach not taken in other studies in this field.

There are several limitations to our work. First, one could argue that our store access variables were not true measures of access, since they were all referent to the store in which the household bought most of its food, which was not necessarily the nearest store to the residence (or even close by). This could imply that supermarket shopping is an issue of choice rather than access. However, other data from the NFSPS dispel this notion. For example, when asked why they did not do most of their food shopping at supermarkets, over $90 \%$ of nonsupermarket shoppers gave answers indicating a lack of access to a reasonably priced supermarket.

Even with evidence that inaccessibility was the main determinant for not shopping at supermarkets, we cannot claim that easy access caused an increase in fruit consumption. Some could argue that supermarkets, like any business, choose locations where demand for their products is high. Thus, it is not that nearby supermarkets caused the increased consumption, but rather owners chose to put supermarkets in areas where they knew consumption would be high. This argument may not be as relevant here, given that our study investigates only a few of the large number of products available in supermarkets. Still, as Cummins has pointed out, cause-and-effect conclusions on dietary effects of store access require an experimental design ${ }^{13}$.

For both ethical and legal reasons, random assignment of Food Stamp Program participants to a control group with no access to supermarkets is obviously not possible. We used multivariate analysis to control for the observed characteristics that could confound the relationship between access and consumption. However, other unmeasured characteristics might have accounted for the relationship we observed. Households that chose to shop at supermarkets may have done so specifically because 
they were motivated to consume more fruits and vegetables. If true, the exclusion of this motivation from the regression model could have biased the coefficients on the supermarket variable. Our joint model in Table 3 included two variables which proxy for this nutrition motivation, one that assessed the respondent's attitude towards nutritious dietary choices and a second that assessed their awareness of dietary recommendations. These results indicate that the supermarket accessconsumption relationship remained, even after controlling for attitudes and awareness about diet.

Since information on store distance was self-reported, it is also possible that some households were misclassified into the three groups of our distance-to-store variable ( $\leq 1$ mile, $1-5$ miles, $>5$ miles). But each of these groups comprises a sizeable portion of the sample, which would tend to dampen minor amounts of misclassification. In addition, our principal finding related to distance was that those furthest away ( $>5$ miles) had lower consumption than those closest $(\leq 1$ mile). Minor errors in distance estimation would probably not have had much impact on this result owing to the large difference in distances between observations in these two categories.

Another possible limitation is that our results are based on food used by the household from at-home food supplies rather than dietary intake of individuals from all sources. This is of particular concern, given the increasing importance of food consumed away from home ${ }^{22}$. If individuals from households with poor access to supermarkets consumed greater amounts of fruits and vegetables away from home than those with easy access, then our results could be misleading; total fruit and vegetable intake might not be associated at all with store access. However, we are not convinced of this argument. First, intake studies have shown that away-from-home food tends to be higher in fats and saturated fats, and lower in fibre, than food consumed at home ${ }^{23}$. Second, despite the rise in consumption of food away from home, a solid majority of meals (71\%) and snacks (78\%) come from home food supplies ${ }^{24}$. This is probably even more pronounced among low-income households.

Nationally representative studies show that fruit consumption is low in the USA, with an average of only 1.5 servings consumed per person per day ${ }^{6}$. Given this panorama, our results, suggesting a 1 serving size difference in fruit consumption due to store access, mean that store access is an important issue, even if only for the limited portion of the Food Stamp population with an access problem. While our results on the relationship of store access to vegetable consumption are less certain, the latter continues to be a dietary problem. Expanding the availability of fruits and vegetables to low-income neighbourhoods, whether through supermarkets or through farmers' markets, would seem an important direction to pursue. Given the relative lack of research in this area, inclusion of an adequate evaluation design in whatever intervention is to be developed should be a priority.

\section{Acknowledgements}

We thank Jim Ohls at Mathematica Policy Research, Inc. for his helpful and generously-given insights on the NFSPS. In addition, we also thank Margaret Andrews, now at the USDA Economic Research Service, and Pat McKinney and Steve Carlson at the USDA Food and Nutrition Service. Without their efforts to make the NFSPS a reality, our work would not have been possible.

\section{References}

1 Ness AR, Powles JW. Fruit and vegetables and cardiovascular disease: a review. International Journal of Epidemiology 1997; 26: 1-13.

2 Steinmetz KA, Potter JD. Vegetables, fruit, and cancer prevention: a review. Journal of the American Dietetic Association 1996; 96: 1027-39.

3 Van Duyn MA, Pivonka E. Overview of the health benefits of fruit and vegetable consumption for the dietetics professional: selected literature. Journal of the American Dietetic Association 2000; 100: 1511-21.

4 US Department of Health and Human Services (DHHS)/US Department of Agriculture (USDA). Nutrition and Your Health: Dietary Guidelines for Americans. Washington, DC: DHHS and USDA, 1980.

5 US Department of Health and Human Services (DHHS). Healthy People 2010. Washington, DC: DHHS, 2000.

6 Krebs-Smith SM, Kantor LS. Choose a variety of fruits and vegetables daily: understanding the complexities. Journal of Nutrition 2001; 131: 487S-501S.

7 Department US of Health, Education, and Welfare (DHEW), Centers for Disease Control. Ten-State Nutrition Survey in the United States, 1968-1970. Preliminary Report to Congress. Atlanta, GA: DHEW, 1971.

8 US Department of Health, Education, and Welfare (DHEW), National Center for Health Statistics. Preliminary Findings of the First Health and Nutrition Examination Survey, United States, 1971-72. DHEW Publication No. (HRA) 74-1219-1. Rockville, MD: DHEW, 1974.

9 McGovern G. Hunger: USA. In: McGovern G, ed. The Third Freedom: Ending Hunger in Our Time. Lanham, MD: Rowman \& Littlefield Publishers, Inc., 2001; 69-82.

10 Kaufman PR, MacDonald JM, Lutz SM, Smallwood DM. Do the Poor Pay More for Food? Item Selection and Price Differences Affect Low-Income Household Food Costs. Agricultural Economic Report No. 759. Washington, DC: Economic Research Service, US Department of Agriculture, 1997.

11 Morland K, Wing S, Diez Roux A. The contextual effect of the local food environment on residents' diets: the Atherosclerosis Risk in Communities Study. American Journal of Public Health 2002; 92: 1761-7.

12 Edmonds J, Baranowski T, Baranowski J, Cullen KW, Myres D. Ecological and socioeconomic correlates of fruit, juice, and vegetable consumption among African-American boys. Preventive Medicine 2001; 32: 476-81.

13 Cummins SCJ. The local food environment and health: some reflections from the United Kingdom. American Journal of Public Health 2003; 93: 521-2.

14 Wrigley N, Warm D, Margetts B. Deprivation, diet and food retail access: findings from the Leeds 'food-deserts' study. Environment \& Planning A 2003; 35: 151-88. 
15 Ohls JC, Ponza M, Moreno L, Zambrowski A, Cohen R. Food Stamp Participants' Access to Food Retailers. Final Report. MPR Reference No. 8243-140. Princeton, NJ: Mathematica Policy Research, Inc., 1999.

16 Food and Nutrition Board, National Research Council. Recommended Dietary Allowances, 10th ed. Washington, DC: National Academy Press, 1989.

17 Gleason P, Rangarajan A, Olson C. Dietary Intake and Dietary Attitudes among Food Stamp Participants and Other Low-Income Individuals. MPR Reference No. 8370-025. Princeton, NJ: Mathematica Policy Research, Inc., 2000.

18 Haines PS, Popkin BM, Guilkey DK, DeVellis R. Knowledge and Attitudes of US Men and Women: The 1989 Diet and Health Knowledge Survey and the 1989 Continuing Survey of Food Intakes by Individuals. Human Nutrition Service Technical Reports Phase I-III. Washington, DC: US Department of Agriculture, 1994.

19 US Department of Agriculture (USDA), Center for Nutrition Policy and Promotion. The Food Guide Pyramid. Home and Garden Bulletin 252. Washington, DC: USDA, 1996.

20 US Department of Agriculture, Agricultural Research Service.
USDA National Nutrient Database for Standard Reference [online], Release 16, 2003. Available at: http://www.nal.usda. gov/fnic/foodcomp. Accessed 6 August 2003.

21 Morris PM, Neuhauser L, Campbell C. Food security in rural America: a study of the availability and costs of food. Journal of Nutrition Education 1992; 24: 52S-8S.

22 Putnam J, Allshouse J. Food Consumption, Prices, and Expenditures, 1970-97. Statistical Bulletin No. 965. Washington, DC: Economic Research Service, US Department of Agriculture, 1999.

23 Lin BH, Guthrie J, Blaylock JR. The Diets of America's Children: Influences of Dining Out, Housebold Characteristics, and Nutrition Knowledge. Agricultural Economic Report No. 746. Washington, DC: Economic Research Service, US Department of Agriculture, 1996.

24 Lin BH, Guthrie J, Frazao E. Nutrient contribution of food away from home. In: Frazao E, ed. America's Eating Habits: Changes and Consequences. Washington, DC: Economic Research Service, US Department of Agriculture, 1999; $213-42$. 